\title{
PRICING INNOVATION: LISTENING TO THE SHOPPER AND CONSUMER
}

\author{
Dora Maria Ciobanu (Morosanu) ${ }^{285}$
}

https://doi.org/10.31410/itema.2018.791

\begin{abstract}
The objective of the presented research was to analyze the pricing innovation impact on the different industries in Romania, taking into account best practices within the beer industry and the trend of the healthy food industry that rose in the last years. Price innovation is made usually by pack type based on shopping behavior and also by shopper healthy behavior (for example bio products).

The weight of pricing in shopping decision might be claimed as the most important one but we will detail in the article that the actual importance is different.
\end{abstract}

Keywords: price differentiation, innovation, customer, consumer

\section{Introduction}

$\mathrm{P}$

ricing innovation is a complex concept that came along with multiple innovations among different industries, especially after 2008 crisis. In addition, it is made based on the shopper and consumer needs and decisions and taking into account the profitability of the producer.

This paper examined the pricing innovation concept on the beer industry, how it developed and what was the impact in the last 10 years at company and consumer level.

\section{Analysis}

After the crisis from 2008 that hit EU and had consequences on the FMCG industry as well, with the beer market seeing a serious blow in terms of volumes and profitability, only as of 2011 we can see stabilization and timid growth from year to year.

Figure 1: Romanian Beer market evolution 2007-2011

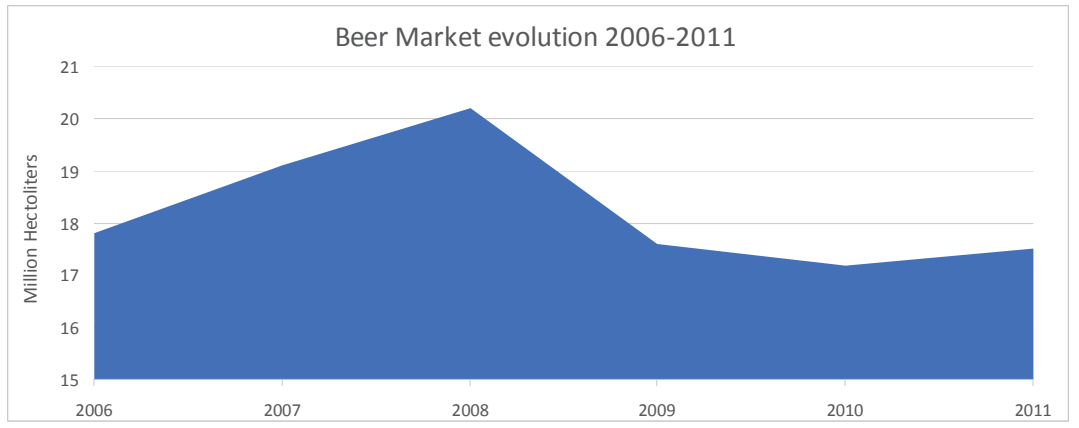

Source: Romanian National Institute of Statistics ${ }^{286}$

\footnotetext{
285 Academy of Economic Studies Bucharest, Street Duetului, no 100, ap 14, district 1, Bucharest, Romania ${ }^{286}$ www.insse.ro
} 
We were writing in $2012^{287}$ that there has been a significant shift in shopper behavior, value brands and private labels brands gaining more than $50 \%$ of the volume share in the beer market (almost all of the volumes being source from low profitability sku's, the PET).

Five years later the reign of the PET, which is a driver for value but also core/mainstream segments, is not over and continues to have a significant impact in the volume growth but also in the top line growth of the beer producers.

We have seen across the years a squeeze in terms of price tiers between value and premium segments which basically means that in terms of pricing there is little or no differentiation between segments. In promotional periods, a premium brand can easily touch pricing points that belong to core plus or even core/mainstream. At the same time the consumer/shopper behavior has changed significantly and the beer brand loyalty has lost importance and for each consumption occasion the beer brands are easily interchangeable.

Figure 2: Beer brands evolution

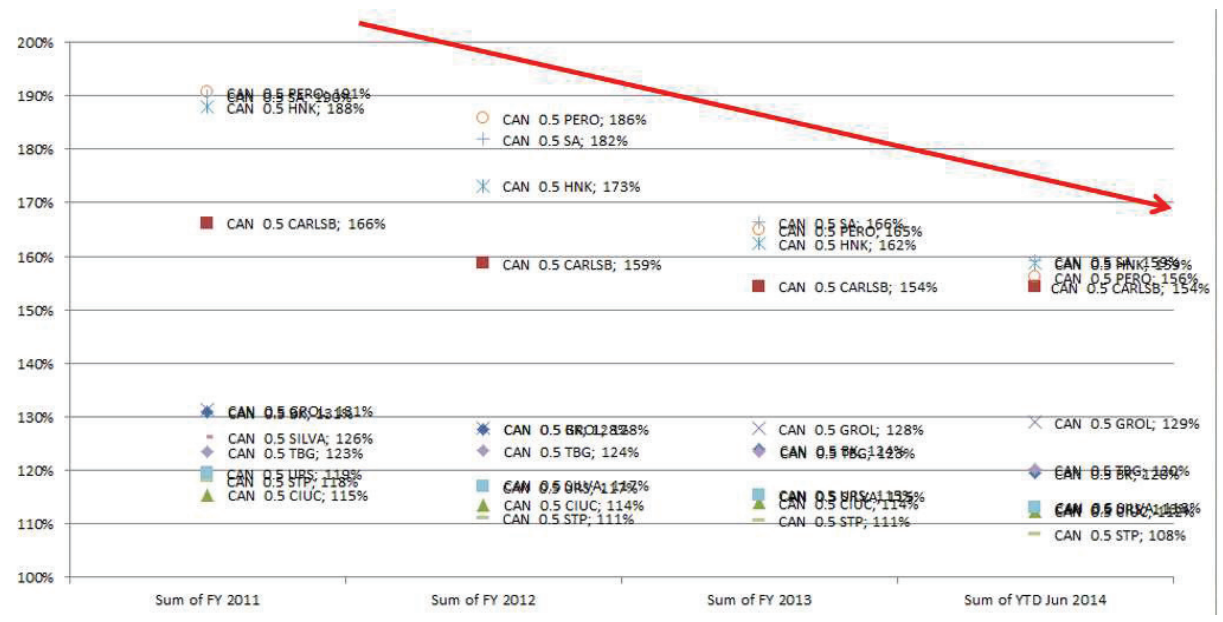

Source: Analysis based on Nielsen Retail data 2011-2014 288

There are some industries in FMCG that are listening to the consumer/shopper behavior and acting upon it through well thought innovations. The healthy lifestyle focus that is currently growing in most of European countries is being addressed by the food industry with significant uplift in terms of pricing and profitability. For example the lactose free, gluten free, vegetable burgers and so on provides room for the food companies to charge from 145 to 260 (price index) versus regular products. Giving less to the consumer/shopper is actually worth more because it acts upon specific consumer needs.

\footnotetext{
${ }^{287}$ Innovation impact on the beer market during economic crisis in Romania - Dora Maria Morosanu, Robert Bumbac

${ }^{288}$ Nielsen Retail data- private source
} 
Figure 3: Price differentia

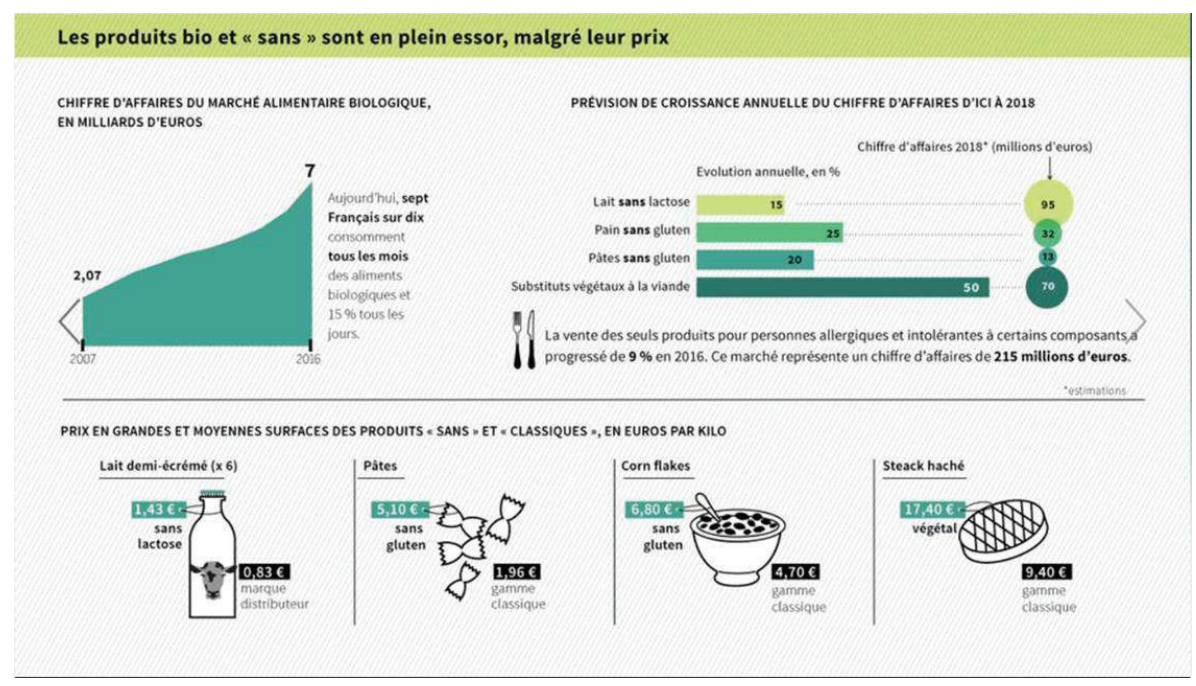

Source: lemonde.fr "Alimentation: a chacun son assiette"289

The actions of the food industry are backed by several researches/studies that have found out that the actual importance of pricing is way less than what the shoppers are actually claiming. In the shopping decision the price is around $10 \%$ in importance, what matters most to the shoppers/consumers are the product/service features and the overall sales experience, which together counts for almost $60 \%$ in purchasing decision.

In order to drive sustainable and profitable businesses, the companies will need to understand more and more that the consumer/shopper is behaving differently that they actually claim, and there is a lot of room to drive profitability by launching innovations that actually listen to the consumer needs and are priced accordingly.

Figure 4: Percent average price importance

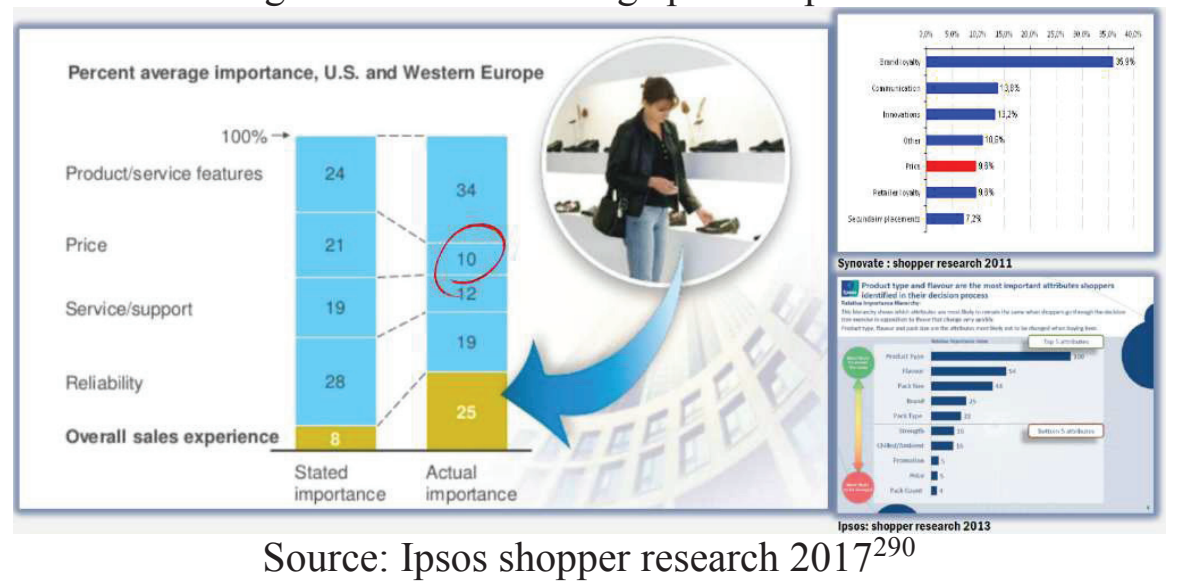

Considering all of the above there is one more thing to be taken into account: innovation doesn't mean only launching new products but also looking at the sizing and selling story of the benefits. A great example from a fresh drinks/ healthy producer shows how to price profitable smaller sized product. By claiming the "vitality"/ "detoxify" / "wellness" / "immunity" shot

\footnotetext{
289 www.lemonde.fr

${ }^{290}$ www.ipsos.com
} 
aspect of the product together with the " 1 bill" tactic they are able to price up to 160 index versus the regular sized product. Main point: there is also price innovation, not only product innovation. So why isn't the beer industry able to activate similar tactics?

Figure 5: Price differentiation by pack type

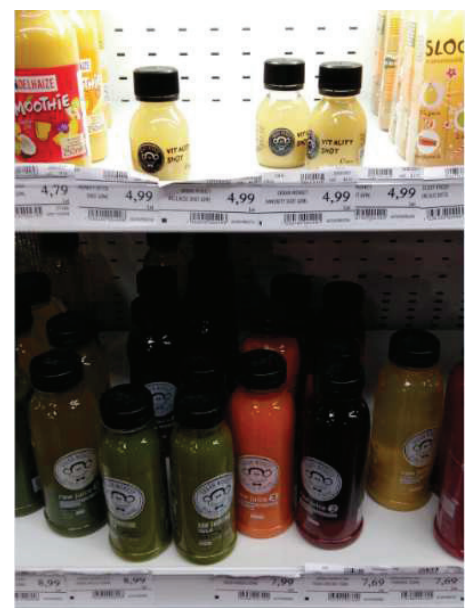

Source: Photo capture from an international retailer in Romania

In the article from 2012 we were writing about the increase of choices in the flavored beer segment, the producers offering more and more flavored variants: lemon, grapefruit, apple, elderflower and so on. Looking back on the approach of the beer producers we can say that they have acted in terms of driving the flavored category by offering new flavors, in appealing primary (returnable bottle, one way, can) and secondary (4 pack, 6 pack etc) packaging, however the pricing innovation aspect has not been activated - all flavors were priced at the same level regardless of the competitor.

The beer industry has a lot of examples in terms of pricing and product innovation that they can activate. Based on the items we listed above, a couple of suggestions can be highlighted:

- Consumer/shopper are looking for product features - opportunity to price differentiate different flavors based on consumer preferences,

- Sizing differentiation based on shopping mission and consumption occasion- perfect serve and benefit claim combined with " 1 bill" out of pocket,

- Healthy lifestyle occasion activation- low/no gluten unfiltered beer propositions,

- Activation/ price differentiation of existing healthy lifestyle proposition - no alcohol/ $0.0 \%$ beer propositions,

- Combination of no alcohol $/ 0.0 \%$ beer propositions with different flavors.

\section{Conclusion}

In maintaining competitive advantage, innovation has a major role in maintaining a company's market share and in consumer/ client loyalty. The frequent changes in consumer behavior and consumer lifestyle also have a strong impact on product development and innovation. Thus, price innovation is associated with the growth and survival of a company.

The causes of price innovation in organizations are especially the need for companies to grow and keep their position on the market being the most important factor because all companies 
are concerned about maintaining market share and increasing it, and the need to diversify production relative to demand (different pack size).

The product lifecycle has been considerably shorter in recent years as competitors in the market struggle to create and launch new, innovative or improved products through superior or additional features, benefiting from the rapid evolution of technology. This sustained pace of product development has many consequences such as low consumer loyalty, greater product differentiation, increased importance of marketing and advertising, large investment of resources to achieve competitive advantages.

The frequent changes in buying behavior and in consumer lifestyle also have a strong impact on product development and innovation, continuously seeking to meet their requirements and needs.

\section{References}

[1] www.insse.ro

[2] Innovation impact on the beer market during economic crisis in Romania - Dora Maria Morosanu, Robert Bumbac

[3] Nielsen Retail data- private source

[4] www.lemonde.fr

[5] www.ipsos.com 